\title{
Medical education and COVID-19 pandemic: a crisis management model towards an evolutionary pathway
}

\author{
Zahra Karimian $^{1,2}$ (D) Majid Reza Farrokhi ${ }^{3,4}$ (D) Mohsen Moghadami ${ }^{5}$ (D) \\ Nahid Zarifsanaiey ${ }^{1}$ (D) Manoosh Mehrabi $^{1}$ (D) Laleh Khojasteh $^{6}$ (D) \\ Nasim Salehi ${ }^{7}$
}

Received: 8 March 2021 / Accepted: 29 July 2021 / Published online: 20 September 2021

(C) The Author(s), under exclusive licence to Springer Science+Business Media, LLC, part of Springer Nature 2021

\begin{abstract}
The COVID-19 crisis has had a profound effect on higher education, especially medical education due to its sensitive nature, dealing with people's life and wellbeing. This study presented a crisis management model of how to direct medical education during crises. A qualitative design was used via a focus group among 83 medical education administrators at Shiraz University of Medical Sciences. Four major challenges emerged regarding medical education during the COVID-19 pandemic including "The health and wellbeing of faculty members and students"; "Spatial constraints"; "Time constraints", and "Access to resources". A total of 13 strategies were suggested to tackle the challenges, including virtualization, technological support, empowerment, participation, sharing, helping, integration, compression, omission, flexibility and diversity, severance, protection; and monitoring. For a sustainable educational pathway in medical education, personalized approach to education via the incorporation of technology is essential. This provides opportunities to tackle the issues caused by the crisis, by provision of any time and anywhere approach to education via flexible technologies/platforms adjusted based on the audiences. The scope of crisis management expands not only on individual and academic levels but also on social and global relations.
\end{abstract}

Keywords COVID-19 $\cdot$ Medical education $\cdot$ Crisis management $\cdot$ SWOT $\cdot$ Pandemic

Majid Reza Farrokhi

Farokhim@sums.ac.ir; Farokhi.sums@gmail.com

Extended author information available on the last page of the article 


\section{Background}

Crises can result in a significant negative impact on the financial, environmental, and social aspects of societies (Mofijur et al., 2021; Bradley et al., 2014). Iran has been ranked among the top ten countries with a high risk of disaster (more than 30 of the 41 natural disasters have occurred in this country) (Mehrabi, 2014). COVID-19 has been considered the biggest challenge in the world after world war two. The first human cases of COVID-19 were first identified in Wuhan, China, in late December 2019 (Holshue et al., 2020; Perlman, 2020), and then rapidly spread to 114 countries across the 6 continents (Guo et al. 2020). South Korea, Italy, and Iran were among the countries most affected by COVID19 shortly after China (Kenneth McIntosh 2019). In Iran, COVID-19 was first identified in the central city of Qom, in late 2019, then the virus spread to other major cities such as Tehran, Rasht, and Shiraz (Taghrir et al., 2020). This is not the first time that diseases have caused a disaster. Following SARS coronavirus in 2002, H1N1 influenza in 2009, and MERSE (9), COVID-19 is the fourth serious outbreak. However, the challenges caused by the COVID-19 pandemic and its profound toll on people's lives are unprecedented. The spread of COVID-19 with a long incubation period, high mortality rate, high transmission rate, and its impact on the long-term cessation of social and economic activities requires special attention and implementing different crisis management strategies (Cascella et al., 2021; Rose, 2020; Choi et al., 2020). Reduction of physical interaction has been the most common strategy across the world to prevent the progress of the pandemic, including the closure of schools/universities, limitations on public transportation, travel and movement restrictions (Rose, 2020; O'Byrne et al., 2020; O’Byrne et al., 2020; Gao et al., 2020).

The educational system was one of the key areas impacted by COVID-19 (Rose, 2020; Doshmangir et al., 2020). According to a recent report by UNESCO (2020), more than 1.5 billion students from 190 countries have been forced to shift from face-to-face education to online learning (Doshmangir et al., 2020). The effects of COVID-19 have been far greater for medical universities and overall health-related disciplines, due to its sensitive nature (e.g., students' placements in healthcare settings and hence, high exposure to the virus) (Rose, 2020; Affouneh et al., 2020; Sahi et al., 2020; Wayne et al., 2020; Loomis et al., 2017). In addition, time restrictions and shortage of healthcare resources and support services further impact the education of medical and allied health students in healthcare settings (Sahi et al., 2020). None of the developed or developing countries was an exception to these fundamental changes (e.g., the United States, the United Kingdom, and Australia) (Burki, 2020). Interestingly, some of the developing countries (e.g., Palestine, Syria, Afghanistan, and South of Africa) that used e-learning in emergency situations, currently planning to shift towards online education after the pandemic (Burki, 2020; Czerniewicz et al., 2019; Shraim \& Khlaif, 2010; Traxler et al., 2019). Online learning has always been at the heart of medical education management at the time of crisis, due to the "physical distance factor" as a spatial constraint and a long incubation period as a "time constraint" in COVID-19 (Rose, 2020; Burki, 2020; Burki, 2020; 
Czerniewicz et al., 2019; Shraim \& Khlaif, 2010; Traxler et al., 2019; Affouneh et al., 2020; 2020 Sahi et al., 2020; Lomis et al., 2017; Ebrahimi et al., 2020; Hilburg et al., 2020; Chen and Mullen, 2020).

Medical education in Iran functions differently, as it is offered through integration with the healthcare system, under the Ministry of Health and Medical Education (that is responsible for both crises management in disease control as well as medical education) (Gaillard \& Mercer, 2012; Marandi, 1996). Following the COVID-19 outbreak, Iranian medical universities and accordingly Shiraz University of Medical Sciences (SUMS) rapidly transitioned the entire curriculum to online formats (Taghrir et al., 2020; Lomis et al., 2017; Aghakhani and Shalbafan 2020). Despite the availability of some e-learning platforms before the COVID-19 pandemic, there was significant resistance to online education due to a lack of competency, and organisational support. In addition, the nature of medical and allied health sciences requires a more practical and hands-on approach to education, and practicality associated with face-to-face teaching methods may not be fully observed in a virtual online platform (Rose, 2020; O’Byrne 2020; Affouneh et al., 2020; 2020). However, the associated high-risk exposure to medical and allied health students and the necessity of observing social distancing makes it inevitable to pose restrictions on universities. Restrictions on education (e.g., placements, internships) significantly impact both education and healthcare services in the short and long term (Rose, 2020; Burki 2020; Burki, 2020; Czerniewicz et al., 2019; Shraim \& Khlaif, 2010; Traxler et al., 2019; Affouneh et al., 2020; Sahi et al. 2020; Sahi et al., 2020; Lomis et al. 2017; Aghakhani \& Shalbafan, 2020). Furthermore, there is great resistance from faculties that e-learning could not replace face-to-face teaching methods due to lack of exposure of the students to the real-world issues, as well as lack of sufficient infrastructure (Aghakhani \& Shalbafan, 2020).

To tackle the crisis in medical education during the pandemic, a strategic approach to the healthcare sector should be at the heart of all crises management, to decrease the negative aspects/consequences, and look at the challenge as an opportunity for change and growth (Ferrel \& Ryan, 2020; Lankarani et al., 2013). Crisis management is a systematic process involving a set of active and dynamic practices that include planning, organizing, infrastructure, leadership, and control and it has four recurring phases included mitigation, preparedness, response, and recovery (Burnham 2008). Short and long-term educational decisions and policies, are greatly influenced and informed by the university's current and future infrastructure and resources. Hence, every educational decision and policymaking at the time of crisis must be informed by a careful analysis of the strengths, weaknesses, opportunities, and threats (Ferrel \& Ryan, 2020). Different countries and educational systems may respond/adjust differently (to prevent the gap/interruption in education), based on their resources, infrastructure, and readiness for change (Clark, 2003). This can be different based on the socio-economic situation of each country. For example, in countries with a higher level of support and advanced technology, the adjustment can happen on an accelerated basis (replacement of face-to-face classes with online courses has been a major policy in medical education management in the USA since the outbreak of COVID-19) (Rose, 2020). 
This study presented a crisis management model of how to provide strategic direction to medical education during crises in SUMS. This approach to crisis management can be applicable across different countries, providing a sustainable direction of how to tackle the health education crisis based on the specific characteristics of each educational system.

\section{Methods}

\subsection{Research design}

A qualitative design was used for this study to achieve an in-depth understanding of managing health-related education during pandemic. The qualitative study included a SWOT matrix (Strengths, Weaknesses, Opportunities, and Threats), as well as a combination of online and face-to-face focus groups.

\subsection{Recruitment}

Purposive sampling was used for recruitment. Participants included the university's Vice-Chancellor for Education, heads of faculties and educational deputies, Administrators of Educational development office (EDO), faculty officials, head of the departments, head of Centre of excellence in e-Learning, head of Education Development Centre (EDC), and the representative of faculty members for each faculty (see Table 1). The research population was chosen from a diverse range of faculties with various levels of profession/expertise. Their expansive levels of knowledge, skills, and expertise in health-related education, as well as its management/administration, provided complimentary and in-depth information around managing the educational system in the current crisis. The research population was in a great position to analyze the situation, its impacting factors from different perspectives, and provide a practical, and at the same time, integrated strategic direction for change.

\subsection{Data collection}

The SWOT matrix (Strengths, Weaknesses, Opportunities, and Threats) was used via a combination of online and face-to-face focus groups (if required). Focus group methods are more appropriate in crises situation, allowing a more holistic brainstorming (Kitzinger, 1995).

Notably, the first part of the study (to design the crisis model) was conducted just after a month after the pandemic. Concerning the necessity of observing social distancing protocols, the education specialists, the university's vice chancellor for Education, the educational deputies, the EDO faculty officials, the EDC managers, and the e-learning scientific pole officials were interviewed using a face-to-face focus group method.

The remainder of the participants joined the first group of interviewees through video conferencing. Before the research, the purpose of this study was 


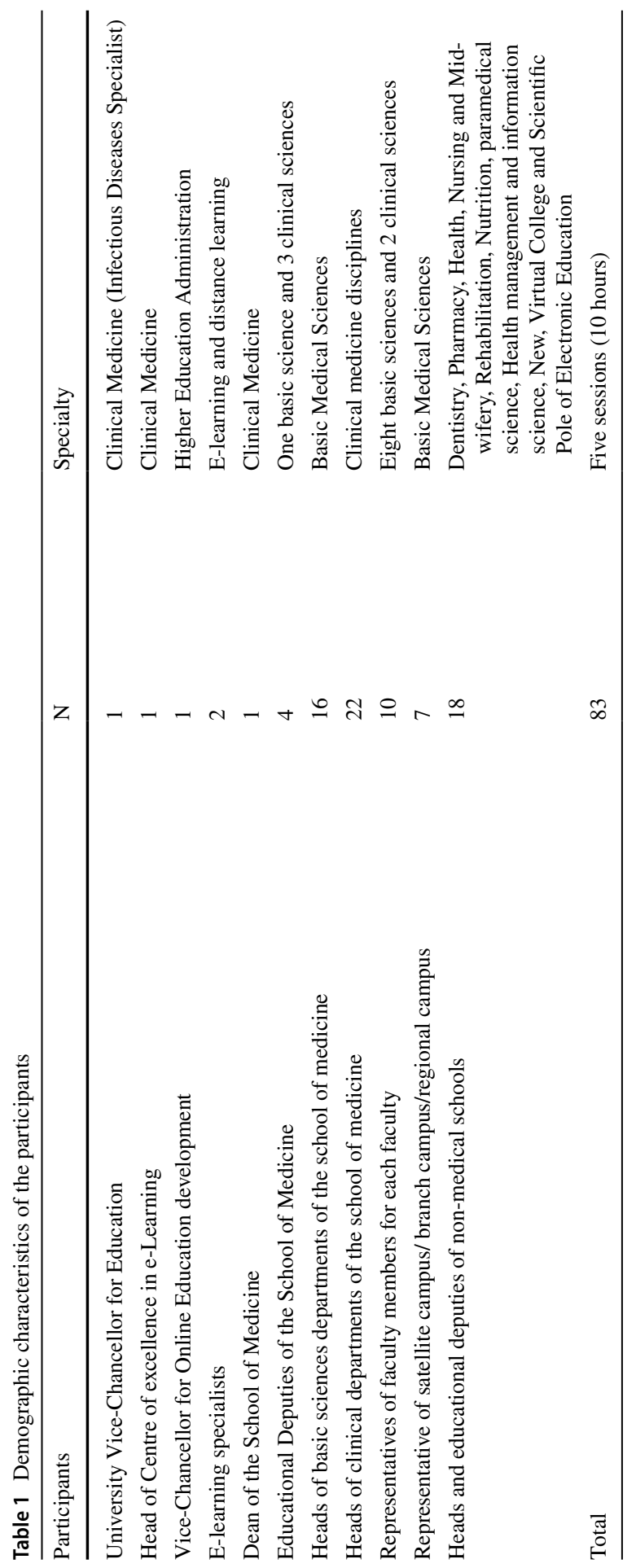


explained to participants and they completed the informed consent. All participants expressed their informed consent to participate in the study verbally, and they were assured that the data would be analyzed anonymously. Analysis of COVID-19 crisis management proceeded in three stages:

- Identifying the main educational challenges related to COVID-19, based on literature review as well as experts' opinions. Keywords searched included "Medical Education" and "COVID-19", "Medical Education" and "Crisis", "Medical Education" and "Pandemic" and "NCBI". An example of database search was the National Center for Biotechnology Information (NCBI) database were reviewed and classified.

- SWOT analysis (using the focus group method and analyzing experts' opinions in two rounds).

- Provision of strategies to overcome the educational crisis in the outbreak of COVID-19 (content analysis of expert opinions and analysis of the strengths, weaknesses, opportunities, and threats through integrated matrixes)

Five focus group sessions ( $2 \mathrm{~h}$ each) were conducted during one month to identify strategies for tackling the educational crisis during COVID-19 via SWOT analysis (The SWOT analysis results were posted to participants for rating via a Delphi method (one round).

\subsection{Data analysis}

Inductive content analysis was used for data analysis, including three stages. In the first stage, a total of 110 initial codes/items were identified and extracted, concerning the suggestions for overcoming the COVID-19 challenges. In the second stage, by removing duplications, 59 codes remained. In the third stage, based on the inferred semantic and conceptual commonalities of codes, in a reciprocal mental process, 59 items were categorized into 13 main strategies. Of these 13 strategies, 12 strategies were in fact responses to each challenge attributed to the relevant items, and one strategy was considered as the core and Monitoring strategy. In the final stage, four key themes were proposed, underlying the key challenges that medical education confront during COVID-19. After that, the 13 startegies were interconnected to the four challenges, based on their relavnec to faciliate the challegnes.

\section{Results}

Based on the literature review, and perspective of 83 specialists participating in the focus groups, it was identified that COVID-19 impacted four aspects of education, making education challenging. 


\subsection{Challenges}

1. Place-COVID-19 impacted the place of education, due to its social distancing, which decreased the physical presence of students in educational settings, classrooms, internships, clinical settings, and dormitories.

2. Time-COVID-19 impacted education more toward asynchronous online education, which does not rely on a specific time and place.

3. Resources-COVID-19 impacted the resource accessibility for education. Due to spatial and temporal constraints and the necessity of closing universities, the students' access to face-to-face classes, interaction with professors, attendance at clinical settings, consulting the library, and physical presence at educational environments were not possible.

4. Health: COVID-19 is highly contagious, has a long incubation period, rapid spread, a lengthy treatment period, and a prolonged pandemic control course. The risks and consequences of the disease are very severe, and protective mechanisms are needed. This results in more pronounced medical sciences, which require more direct encounters with high-risk environments.

All of these challenges have directly affected education in all disciplines (particularly medical science education). Even though online infrastructures such as the national LMS of Iranian universities of medical sciences (NAVID) have been available before the outbreak of COVID-19, faculty members had not shown much interest in implementing them in their courses. Therefore, most medical universities, including SUMS did not have much experience in using e-learning, so the dominant approach was faceto-face training. However, for the existence of the Centre of excellence in e-Learning in the SUMS, many instructors had received basic training in e-learning. After reviewing the existing challenges/information based on the SWOT analysis and the perspective of experts, the following was identified:

\subsection{SWOT analysis to identify a strategic direction for health education}

\subsubsection{Strengths}

- Existence of a virtual school and center of excellence in e-learning

- Existence of Learning Management System (LMS) infrastructure

- Conducting e-learning software training courses, existing introductory courses on e-learning, and familiarity of the faculty members with e-learning

- Availability of facilities and equipment for developing the e-content (Studio room, cameras, etc.)

- Access to more than 700 online e-contents

- Availability of a centralized electronic exam platform for conducting online exams

\subsubsection{Weaknesses}

- Faculty members showed no or little interest in online education as a necessity for medical education before the COVID-19 outbreak. 
- Faculty members lack expertise for producing e-contents, working with LMS, as well as low computer skills

- Lack of motivation to substitute face-to-face classes for online ones.

- Insufficient training of faculty members and educational experts.

- Lack of a reliable and valid procedure for student assessment.

\subsubsection{Opportunities}

- The accordance of national macro-policies with online education policies at the micro-level.

- Conceptual development of the online education concepts through the educational reform and innovation plan.

- Availability of the national LMS infrastructure (NAVID).

- Monitoring the educational activities of universities through the national system (Rayaban).

- Timely reporting and monitoring of educational activities at each university.

\subsubsection{Threats}

- The impact of COVID-19 on the closure of educational settings

- Insufficient preparation of professors and students for the COVID-19 crisis.

- Lack of access to online learning facilities, particularly hardware (laptops, computers) for some students.

- Difficulty accessing the Internet and infrastructure in some parts of the country (nomads, villages).

- Difficulty in financing the Internet to access and download course contents and upload homework.

- Some technical problems of national LMS (NAVID).

- Professors' and students' unfamiliarity with national LMS (NAVID) before COVID-19.

- Integrated nature of medical education with health services at SUMS and other Iranian medical universities. Iran is the only country where medical education is offered separately from other academic disciplines and under the supervision of the Ministry of Health).

\subsection{Determining strategic directions}

In the third stage, 5 consensus meetings were held to discuss the strategies for overcoming the educational crisis resulting from the consequences of the COVID-19 pandemic were developed using Matrix Factorization. In the meeting held to determine and approve the crisis management strategies in medical education, a list of strategies was sent to all of the participants and validated by them. Finally, $12+1$ strategies and actions were approved with the consensus of about 75 to 100 percent of the experts (the final strategy was used as an assessment of the last 12 strategies). Then, the defined strategies for each challenge were determined. For the 4 main 
challenges, a total of 12 specific strategies and 50 actions were developed and one general strategy included 10 Actions was used to monitor the training in all stages. A summary of all results is shown in Table 2.

\subsection{Transition to LMS and its interactive mode}

A total of 2850 courses were offered (to 10 faculties) in the semester that pandemic occurred. None of the educators and students were familiar with National LMS (NAVID), before the COVID-19 Pandemic. The LMS was available to all 10 faculty members and students, including a diverse range of activities via synchronous and asynchronous styles (e.g., formative tests, discussion board forums, virtual classes). LMS (NAVID) allows to transfer and share all types of files such as images, audio, video, and texts between students and educators. In addition, communication was accessible for teacher-student, teacher-teacher, and student-student through the messaging system. Along with the use of the LMS platform for asynchronous activities, it was possible to hold virtual classes simultaneously for all courses in a synchronous way. There were opportunities to use Adobe Connect software to create and manage virtual classes. Educators had some levels of flexibility to use a diverse range of software for their virtual simultaneous classes, including BigBluebutton, Skype, Skyroom, and Zoom. Support services were provided by the Virtual Education Center if required.

It is noteworthy that before the COVID-19 pandemic, about 700 e-contents of the most widely used courses/subjects for most basic medical sciences (biochemistry, pharmacology, paramedical courses, general courses, etc.) were prepared, which facilitated the transition to the online system during the pandemic and extend on that 700 existing e-content.

\subsection{Training, and adjustment to LMS}

Due to the lack of experience of educators and students in regards to e-learning, more than 50 online workshops, and 20 educational guidelines were developed and presented synchronously and asynchronously for students and teachers.

The percentage of active teachers and students was monitored regularly, monthly. This provided a direction in regards to their engagement and the need for further training and online learning infrastructure. As Fig. 1 indicates despite the low level of expertise regarding online education, the number of active students and educators has increased significantly.

As educators had more access to e-learning facilities than students, as the figure shows, the slope of students' activities in LMS is less than educators. Therefore, in addition to the formal infrastructure, mobile-based social networks were incorporated for education, due to their accessibility and ease of use.

In regards to clinical education, which requires presence in the healthcare settings, practical classes in the first year of the clinical course for all fields of study, were closed, as they generally consist of observing clinical procedures. Practical video-based classes were used instead. However, the final year students, who were 
Table 2 Challenges, strategies and practical actions in crisis management of medical education during COVID-19 pandemic in SUMS

Challenge: Place (Physical distance)

\begin{tabular}{|c|c|}
\hline Strategy & Actions \\
\hline Virtualization & $\begin{array}{l}\text { 1. Adopting a virtualization strategy in all educational activities of students } \\
\text { and assistants } \\
\text { 2. Access to the NAVID platform to conduct theoretical, practical courses, } \\
\text { and dissertations ( } 2850 \text { courses/subjects/units from } 10 \text { faculties) } \\
\text { 3. Using discussion modules, giving assignments, developing tests, and } \\
\text { sending/receiving messages via the LMS (NAVID) platform } \\
\text { 4. Enabling access to virtual classroom system(s) for conducting synchro- } \\
\text { nous courses in all educational groups } \\
\text { Suggestions for offering } 30-70 \text { percent of the theoretical courses in an asyn- } \\
\text { chronous format and } 70-30 \text { percent in the form of synchronous } \\
\text { 5. Giving the authority and autonomy to faculty members and departments } \\
\text { to decide about the volume of the synchronous and asynchronous method } \\
\text { according to the nature of the course, and the facilities and conditions of } \\
\text { the students and faculty members } \\
\text { 6. Conducting at least } 30 \% \text { of the courses in synchronous format for more } \\
\text { teacher-student interaction } \\
\text { 7. Providing clinical rounds, journal clubs, and clinical discussions through } \\
\text { virtual education } \\
\text { 8. Offering part of the practical and internship courses by uploading educa- } \\
\text { tional videos }\end{array}$ \\
\hline Support system & $\begin{array}{l}\text { 9. Creating cluster groups with a focus on three levels: a) Virtual Educa- } \\
\text { tion Centres for empowerment and support of educational technologists, } \\
\text { b) faculty members by assisting them to implement virtual courses, and } \\
\text { c) students through teacher-student communication and educational plat- } \\
\text { form, social media, email, website) } \\
\text { 10. Create an online technical/IT support system in LMS to respond and fix } \\
\text { technical problems related to both students and educators } \\
\text { 11. Creating a social network of officials and middlemen for better com- } \\
\text { munication and information transfer }\end{array}$ \\
\hline
\end{tabular}

Challenge: Access to resources

\begin{tabular}{ll}
\hline Strategy & Actions \\
\hline Empowerment & 12. In-person meetings with faculty members who are less familiar with \\
virtual education and providing basic information on how to work with \\
software and electronic infrastructure (i.e. LMS) \\
13. Conducting meetings with guidelines on how to work with the LMS \\
infrastructure, conduct virtual courses, and use content development soft- \\
ware with synchronous and asynchronous methods \\
14. Preparation of multimedia files with guidelines on how to work with \\
e-content development software and sharing the software for the teachers \\
15. Creating a website/page for training the professors to use the infrastruc- \\
ture and software \\
16. Preparing guidelines on how to operate electronic systems and work with \\
blended learning modules \\
17. Sharing e-guides through websites, emails, and social networks \\
18. Involvement of faculty members (particularly general courses) in the \\
development of e-contents and educational packages) \\
19. Involvement of faculty members in the preparation of educational videos \\
to provide practical and internship courses \\
Participation
\end{tabular}


Table 2 (continued)

Challenge: Access to resources

\begin{tabular}{ll}
\hline Strategy & Actions \\
\hline Sharing & 20. Sharing the link of offline training programs that provide basic training \\
on how to use educational software \\
21. Develop the national electronic library for medical sciences \\
22. Offer to share educational content and videos nationally in medical \\
universities \\
23. Exchanging experiences and responding to questions in social network- \\
ing groups \\
24. Synching and integrating all educational management system (LMS, \\
E-Exam platform, and central educational system) \\
25. Contacting the national NAVID support group for feedback and Ask for \\
help fixing bugs \\
26. Contacting faculty members and faculty experts for problem-solving and \\
information transfer \\
27. Attracting the participation of charities to finance the electronic equip- \\
ment of low-income students
\end{tabular}

Challenge: Time (Time limitation)

\begin{tabular}{|c|c|}
\hline Strategy & Actions \\
\hline Integration & $\begin{array}{l}\text { 28. Integration of some similar general courses in virtual classrooms to save } \\
\text { time } \\
\text { 29. Allocation of the saved time to building integrated e-content for near } \\
\text { disciplines and similar courses }\end{array}$ \\
\hline Compression & $\begin{array}{l}\text { 30. Offering the theoretical courses in the first three months following } \\
\text { the COVID-19 outbreak through the LMS platform and virtual classes; } \\
\text { allocating the remaining time to short face-to-face courses at the end of the } \\
\text { semester for practical courses } \\
\text { 31. Compressing and decreasing the duration of internships to } 50-60 \% \text { of } \\
\text { the usual time (addressing only Must Learn topics) }\end{array}$ \\
\hline Omission & $\begin{array}{l}\text { 32. Exclusion of } 20-30 \% \text { of the none core course contents (Nice to learn of } \\
\text { the curriculum) and assigning them for self-study } \\
\text { 33. Giving the students the authority to drop off a course or omit the semes- } \\
\text { ter }\end{array}$ \\
\hline Flexibility and Diversity & $\begin{array}{l}\text { 34. Replacing in-person final exams with homework, project, and classroom } \\
\text { activities } \\
\text { 35. Flexibility in setting standards for the quality of electronic content in } \\
\text { disaster situations } \\
\text { 36. Flexibility in educational design with synchronous and asynchronous } \\
\text { methods considering the requirements for conducting blended learning } \\
\text { 37. Variety of teaching methods and educational assessment procedures } \\
\text { 38. Using different information transfer methods and the education of faculty } \\
\text { members (i.e. online, offline, in-person) } \\
\text { 39. Flexibility in providing course units and defining prerequisites } \\
\text { 40. Devoting } 30-50 \% \text { of the course credit to projects, homework, and prac- } \\
\text { tice via LMS; and 50-70\% of the course credit to final exams }\end{array}$ \\
\hline
\end{tabular}


Table 2 (continued)

Challenge: Health (Risks of the pandemic, for health-related disciplines)

\begin{tabular}{ll}
\hline Strategy & Actions \\
\hline Severance & 41. Cancellation of all face-to-face theoretical courses and closure of student \\
dormitories to lower the exposure risk and observe the principles of social \\
distancing \\
42. Separation of training beds from normal hospital beds for student intern- \\
ships \\
43. Dedication of special training hospitals to clinical training \\
44. Cancelation of all dentistry internships because of the high exposure risk \\
and training only through instructional videos \\
45. Postponement of dental internships to the time that the COVID-19 is \\
contained \\
46. Providing protective equipment for medical teams \\
47. Providing protective equipment for interns in training courses \\
48. Allocation of a single bedroom to each student during the peak of the \\
exams \\
49. Availability of disinfection equipment and materials for clinical interns \\
during internship WHO protocols
\end{tabular}

Core Strategy

Monitoring, Supervising, evaluation, and feedback
50. Regular monitoring of the educational performance in terms of the use of the LMS interactive modules

51. Regular monitoring of the university's educational status in terms of the number of active professors, active students, and active courses on the LMS platform

52. Submitting regular periodic reports to the educational deputies of the faculties

53. Preparation of guidelines for the production of standard e-content to improve their quality

54. Providing regular weekly reports on the status of the educational activities in the meetings of the COVID-19 crisis management committee

55. Development of new teacher evaluation forms based on virtual training, virtual grand rounds, virtual classes, virtual workshops, etc.)

56. Employing research plans and running a needs analysis to control the quality of the e-content

57. Conducting Studies on the Challenges of Virtual Education in Pandemic COVID-19 from the Students' Perspective

58. Conducting Studies on the Challenges of Virtual Education in Pandemic COVID-19 from the Teacherss' Perspective

59. Conducting studies on the quality of e-content and synchronous and asynchronous methods and other aspects of e-learning

in the course of practical activities, attended the clinical settings based on COVID19 protocols, and clinical assistants presented in hospitals and educational settings during the training.

\subsection{LMS enhancement and bug fixes}

Because national LMS was a new infrastructure and had not been used before the pandemic, opportunities were provided for regular feedback (e.g., daily, weekly, 


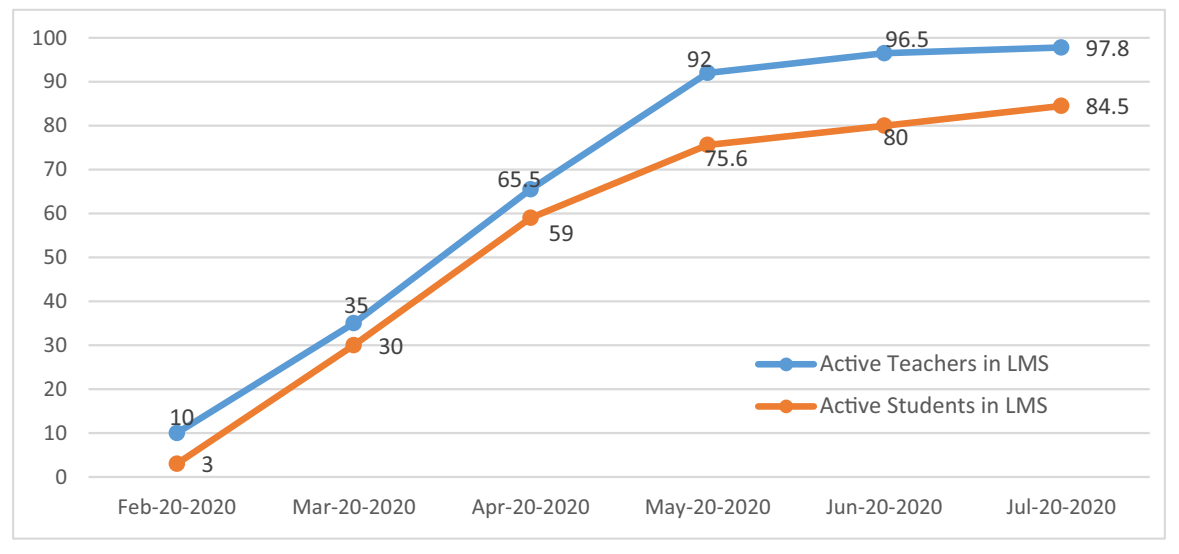

Figure1 Percentage of active participation of teachers and students in the use of LMS in the semester coinciding with the outbreak of COVID-19

monthly, and the end of the semester feedback). In addition, a joint social network group was established between the members of the Center of Excellence in E-Learning(CEEL), faculty members, and students, and instant feedback was reviewed and followed up. These provided great opportunities to identify LMS bugs and assist with instant maintenance.

\subsection{LMS reporting indicators}

LMS system provided opportunities to assess the performance in each university. Some examples are the number of uploaded e-Content, assignments and exercises, formative tests, and discussion board, the number of activities provided by the teachers, the number of activities performed by the student, and the number of feedback exchanged between the teachers and the students. In addition, it was possible to compare universities' performance. Given that in the semester coinciding with COVID-19, all universities used the same LMS, the Virtual University of Medical Sciences (VUMS), as the head/administrator of the National LMS, monitored the activity of universities in interactive modules and quarterly reports were sent to universities.

\section{Discussion}

This study highlights some key points concerning the challenges caused by the COVID-19 as well as how this pandemic resulted in some sort of evolution in online education, particularly in health-related disciplines, due to their sensitive nature. Pandemic resulted in a major unexpected interruption in education due to two fundamental and interconnected factors, at two levels. At the individual level faculty members and students were not ready to move to online education. For example, 
faculty members did not have the sufficient skills and expertise for online education, and students were confused about how to adjust/adapt. At the macro/societal level, there was a lack of infrastructure and support for online education. A complex example can be the practical health disciplines (e.g., medicine and nursing) that require more practical approaches to education (placements) which were not easily manageable by online teaching due to the expenses and complexity of the case. Practical and online health-related education requires more advanced online platforms for simulation purposes, such as virtual reality, and at the same time, these technologies have their limitations (the social and emotional aspects of care may be missed in online education). Overall, these two interconnected factors at the individual and organizational level resulted in a chaotic transition and put a lot of pressure on both faculty members and students. This was more severe for first-year students, as the university environment was quite new to them, let alone all the change/interruption due to the transition.

The positive aspect of COVID-19 was the creation of a situation that everyone felt responsible to adjust to the new normal on time. Hence, this resulted in significant advanced education/learning around online education techniques/platforms, in a short period that might have not been possible to achieve in a normal time. In past, moving towards online education and/or blended learning, was a slow process in health-related disciplines in Iran, which was facilitated by the current pandemic. In addition, the pandemic resulted in a more cohesive workplace that enhanced the level of collaboration/cooperation and team working more strategically, as there was an attitude that "we are all in this together". The pandemic resulted in thinking seriously about the vision of education, the importance of strategic planning, mission, values, and goals, and how to plan for "getting out of the comfort zone" and "look at the challenge as an opportunity for growth". Furthermore, some wellbeing outcomes are resulting from this pandemic. First, the pandemic resulted in a higher level of adjustment/change management at different levels and/or for different partners (including students, staff, and policymakers), as well as it resulted in a higher level of collaborations at local, national, and even international levels. This can result in a more secure and healthy working environment for all the partners to be valued/ listened, and generate ideas. Second, online education overall resulted in less paper works and face-to-face presentations, which subsequently lead to a more sustainable environment. All of these positive aspects can results in a more sustainable outcome also towards effective and efficient educational approaches.

COVID-19 has affected all aspects of education particularly the delivery of education, globally. Each country is using specific strategies and/or coping strategies to manage the situation, based on their limited resources. According to Health and Hyogo Framework for Action (2005-2015), five priorities have been suggested to manage the educational-related crises. These are (1) Integrating health into disaster risk reduction as a national and local priority (development and implementation of coordinated multi-sectoral policies and strategies with sufficient resources); (2) Health risk assessment and early warning (assessment of risk and developing management based on hazard, vulnerability, and capacity analysis in conjunction with surveillance and monitoring the potential health threats); (3) Using education and information to build a culture of multilevel health and safety resilience (strengthen 
the knowledge, skills, and attitudes of professionals and promote healthy behaviors); (4) Reduction of underlying risk factors to health systems (addressing poverty, reforming health, and improving vital infrastructure and initiatives to create employment and ensure business continuity); and (5) Emergency preparedness for effective health response and recovery at all levels" (Dar et al., 2014). In the present study, the strategic analysis of SUMS was focused on the four major challenges that the pandemic posed on the educational system, including health, place, time constraints, and limitations in access to resources.

Time and place of education have been significantly impacted by the COVID19. The long incubation period, long recovery period, and the persistence of the disease in communities due to lack of a definitive treatment/vaccine are influential factors, impacting individual and social life. In recent years, the experiences from limited involvement with similar cases have shown that separation, observing social distancing, use of protective equipment, and temporary cancelation of classrooms/internships have been the major strategy in controlling and preventing the spread of high-risk high-prevalence diseases (Rose, 2020; Affouneh et al., 2020). In addition, face-to-face interactive problem-solving discourses in clinical and outpatient settings have always been the undeniable primary experience of involvement in clinical education (Rose, 2020). Ahmed et al., (2020) state that educational suspension related to teaching hospitals could have many negative effects on clinical internships, including the elimination of elective courses (Affouneh et al., 2020). Ferrel and Ryan (2020) argue that although faculty members have partly replaced virtual learning with face-to-face classes, it is very difficult to provide timely and appropriate teacher-student feedback through this platform (Aghakhani \& Shalbafan, 2020). In addition, student-student interaction, the role of peers, and the presence of classmates in the learning contexts have a profound impact on student education. On the other hand, its long-term effects on transcendental and semantic communication, such as role modeling also need to be considered (Lomis et al. 2017). The unknown nature of COVID-19, an increasing prevalence rate, and unanticipated future outcomes necessitate serious attention and planning to counteract the harmful educational impacts of this pandemic on higher education (Rose, 2020; Sahi et al. 2020; Sahi et al., 2020; Dar et al., 2014; Clark, 2003). Understanding the possibility that the pandemic will continue for some time and probably leads to a shortage of resources, such as healthcare staff (medical students may need to be employed as part of the labor force). This in turn requires a more flexible approach to the fulfillment of the requirements of the courses concerning the curriculum development, as well as delivery methods (10).

Overall, COVID-19 can result in evolution to provide more advanced and practical solutions in regards to learning. It seems that during the pandemic, the use of online methods in both synchronous and asynchronous methods is one of the main strategies in education crisis management. This can highlight the importance of new techniques and technology in education, including artificial intelligence to implement virtual reality, and gamification in health-related education. Goh et al., (2020) address online teaching in medical education, through emergent technology, as an integrated component of medical education even after the control of the COVID-19 
outbreak (although it may pose its benefits/challenges) (Patil et al., 2003). Given the limited experience of faculty members and students in using virtual education platforms before the COVID-19 outbreak, it is necessary to provide supportive strategies, such as training and empowerment, information giving, and preparation of training brochures, as well as providing counseling and offering support to the involved groups that is one of the main strategies for adapting to the COVID-19 outbreak.

The health of all involved partners in health-related education is a key factor to consider as presence in the healthcare setting is paramount in a practical education process. Various groups in universities are involved in the process of counteracting the consequences of the pandemic (Traxler et al., 2019). Faculty members, students, educational, and technical experts have been professionally influenced by the disease and have redefined their roles (in the way they provide/receive services). This is extremely important in medical universities and has sometimes led to unavoidable paradoxes in the management of the education crisis during the pandemic. For instance, the field of medical sciences, compared to non-medical ones, has the highest exposure risk; this is due to the direct contact of the personnel with the disease, particularly in dentistry, medicine, and nursing (Taghrir et al., 2020; Rose, 2020; O'Byrne, 2020; Sahi et al., 2020; Loomis et al., 2017). While the professional nature of medical sciences calls for professional commitment and presence in clinical settings and internships, the high exposure risk associated with such disciplines (Rose, 2020; O'Byrne 2020; Affouneh et al., 2020; Sahi 2020; Loomis et al., 2017) has caused most parents to be worried about the presence of their children in such settings. Hence, one of the extremely controversial issues in all medical schools and related disciplines is whether professional commitment must be prioritized over maintaining the students' health and preventing the spread of disease among them (Doshmangir et al., 2020). In this regard, various universities have adopted different policies. Some universities have completely banned students from attending clinical settings and hospitals (Rose, 2020; Affouneh et al., 2020), while in some others, students have been allowed to attend clinical courses and fulfill their professional duties or even voluntarily train or provide healthcare services (considering the COVIDsafe instructions) (O’Byrne 2020; Kitzinger, 1995; Harvey, 2020; Cole, 2020).

One of the most important challenges of e-learning can be the e-examination process and/or the evaluation. Due to the need to observe social distancing, most of the theoretical exams were conducted electronically. This was challenging for faculty members in two ways. First, the electronic nature of the tests and the impossibility of direct and visual monitoring in crowded classrooms always make teachers unsure of the implementation of a reliable exam. The second challenge that professors face in the long run is to lose the value of the test question repository. Because students answer the questions electronically outside the university and from their personal computers, it is possible to record tests and publish the questions, and after a short time, the learning value of the questions is reduced. It seems that using analytical and reasoning questions instead of closed-ended questions, and increasing the share of continuous and gradual evaluation throughout the course, and using individual evaluation methods such as project and practical work can be more effective, more reliable, and importantly, enhance the depth and practicality of learning. 
Resources, educational infrastructure and support system is a fundamental factor for successful educational transition, particularly during the crises. At SUMS, the main policy for pre-clinical students of medicine, dentistry, and para-clinical disciplines has been the cancellation of face-to-face classes (attendance time in clinical settings), with emphasis on the "Must Learn" contents and experiences and omitting the "Nice to Learn", impacting the quality of their education. In addition, for the fact that in the universities of medical sciences in Iran, healthcare services are provided through integration with medical education, to prevent excessive and uncontrolled exposure to various diseases, students were limited to some specific hospitals. This decreased the variation in the practicality of clinical education, based on real-world issues (Rose, 2020; O’Byrne 2020; Affouneh et al., 2020; Sahi et al., 2020; Loomis et al., 2017). To reduce the negative effects of the issue, the University Education Council approved that 30 to 50 percent of the courses must be offered synchronously to allow more interaction between professors and students. In addition, many professors prepared instructional videos (in healthcare settings, such as hospitals) to show practical procedures, based on real-world issues. However, it seems the macro-policy for providing national or global virtual laboratories to creating a bank of shared educational videos is essential.

The socio-economic status of students can be an important factor in educational changes due to the pandemic. Although the students were different in terms of their financial status and access to facilities even before the COVID-19 outbreak, due to the same amount of access to the teacher and the course contents in face-toface classrooms, these differences were less effective on the students' education in such settings. However, due to the dependence of the virtual education system and e-learning on technology and the need to have access to the required hardware and software, these impacts are more evident in such classrooms. Khalif et al. (2020) in a descriptive case study of interviewing 60 participants from three developing countries (Libya, Palestine, and Afghanistan), regarding educational challenges during the COVID-19 pandemic, found that learning environment, hardware and software facilities, and equipment are the main challenges that negatively influenced equitable students' engagement in online classes (Khlaif and Salha 2020). In this regard, universities must provide equal access to education by identifying less prosperous students and providing the necessary tools. In addition, adopting the strategies of "flexibility" and "diversity" is important in providing course contents, teaching methods, instructional design, and evaluation methods, based on a personalized approach.

\section{Conclusion}

A summary of the experience of SUMS, during pandemic has been shown in Fig. 2, indicating the unique phenomenon, that imposes medical education with four challenges, including time, place, health, and access to resources. The scope of these challenges can be seen at individual, academic, social, and even global levels, creating a common educational empathy (e.g., universities across the world are holding joint training webinars and sharing their educational experiences). interesting paradox is that although individual (and particularly face-to-face) 
communications have declined due to social distancing, number of international communications has increased through cyberspace and social media. Numerous international scientific social networks have been formed in Iranian universities, including SUMS, and have connected faculty members from all over the world. We greatly experience how to be more integrated regardless of the place. Since health and education are two key areas for global development, perhaps more than ever, the global consensus is needed to redefine medical education beyond geographical boundaries. This study indicates that we can look at the current pandemic positively, providing an evolutionary process for advanced improvements in education in general, and more particularly in health-related disciplines.

We suggest three key approaches that can be applicable and implemented internationally, as the pandemic is impacting the educational system, globally and there is a significant shift towards online platforms. First, shifting health education towards synchronous or asynchronous approaches to enhance the flexibility

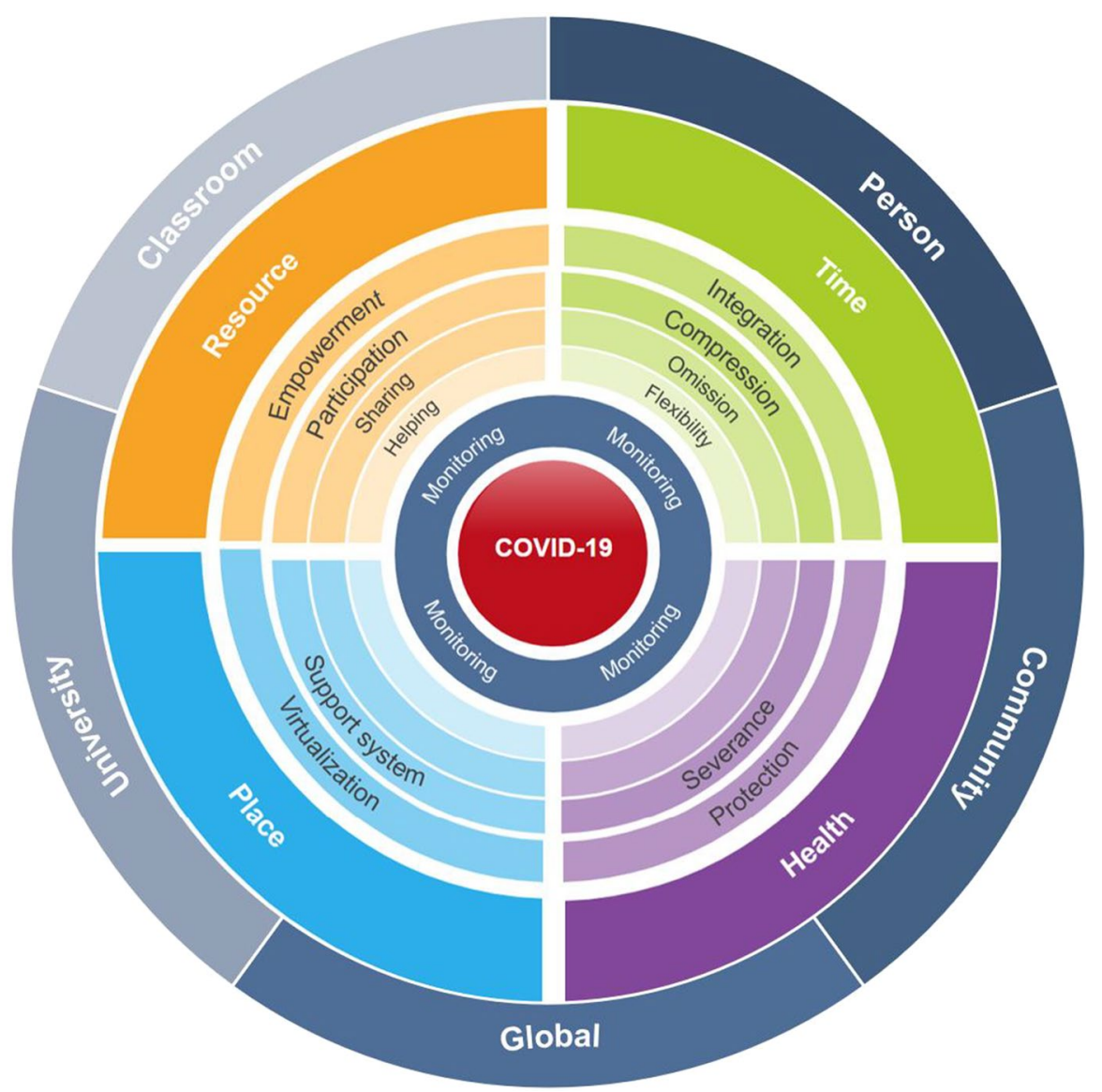

Fig. 2 Crisis management model in medical education during COVID-19 Pandemic 
of learning regardless of any time and place limitations. Second, enhancing personalized approach to learning, which is of particular attention in online teaching because the monitoring and supervision part may be missing. It is paramount to use practical and flexible approaches to students' engagement and learning, based on their capabilities/capacities (not comparing students with each other, but rather monitoring the learning journey of each student separately). Third, leveraging advanced technology in online education, particularly health-related disciplines. The incorporation of technology can include a simple multimodal technological approach to more advanced ones, depending on the discipline and the audience, so one size should not fit all. An example of advanced technology in education can be virtual reality and/or the usage of artificial intelligence techniques for student's placement to create a real-world environment.

To be able to implement the above three approaches, we have four key recommendations to consider. First, having an ecological approach/framework in place to evaluate facilitators and barriers of the new model. Often, the key evaluation focus is students, and their satisfaction/retention, while educators' voices may not be heard. We suggest that any new educational model be assessed regularly by educators as well to evaluate the support services (budgeting, resources). Second, more evidence-based assessment designs, and a smarter approach to marking can be implemented. By incorporating technology, assessments can be more evidence-based and practical, considering real-world scenarios. In addition, more technological approaches can be used for marking assignments (e.g., data mining). Third, nurturing active, collaborative, and multidisciplinary learning approaches. Learning sites can be designed to encourage multidisciplinary engagements to encourage active and real-world learning. It is also important to pay attention to diversity, equity, and students' voice in the new online models (e.g., support techniques are required to connect students to feel part of a group in new teaching and learning space). Fourth, provide the learning designs in a way to assist students to enhance their self-learning, and at the same time, in-depth learning in an online environment, and decrease the risk of surface learning.

Acknowledgements Many thanks to all the managers and faculty members who participated in these focus groups and expressed their valuable opinions in the field of situation analysis, challenge setting, and strategy presentation

Author's contributions Authors contributed to the publication of this article as follows: ZK conducted the literature review for the background and conceptualized of the study, collected data, analyzed the content of participants' opinions, and extracted tables and conceptual models and wrote the manuscript. MR.F and M.M $\mathrm{M}_{1}$ collected data for the study, contributed to study design and supervised oversaw the study critically. N.ZS and $\mathrm{MM}_{2}$ involved in data processing and revised the manuscript critically, L.KH and N.S Translated and edited and revised the manuscript critically. NS contributed in data synthesis and writing of the manuscript. All authors read and approved the final manuscript.

Funding Not applicable.

Data availability The datasets used and/or analysed during the current study are available from the corresponding author on reasonable request. 


\section{Declarations}

Ethical issues The study was approved by the ethic committee of Shiraz University of Medical sciences.

Conflict of Interest The authors declare that they have no competing interests.

\section{References}

Affouneh, S., Salha, S., \& Khlaif, Z. N. (2020). Designing quality E-learning environments for emergency remote teaching in coronavirus crisis. Interdisciplinary Journal of Virtual Learning in Medical Sciences, 11(2), 135-137.

Aghakhani, K., \& Shalbafan, M. (2020). What COVID-19 outbreak in Iran teaches us about virtual medical education. Medical Education Online, 25(1), 1770567. https://doi.org/10.1080/10872981.2020. 1770567

Ahmed, H., Allaf, M., \& Elghazaly, H. (2020). COVID-19 and medical education. The Lancet. Infectious Diseases, 20(7), 777-778. https://doi.org/10.1016/S1473-3099(20)30226-7

Bradley, D. T., McFarland, M., \& Clarke, M. (2014). The effectiveness of disaster risk communication: a systematic review of intervention studies. PLoS Currents, 6, ecurrents.dis.349062e0db1048bb9fc3a 3fa67d8a4f8. https://doi.org/10.1371/currents.dis.349062e0db1048bb9fc3a3fa67d8a4f8.

Burki, T. K. (2020). COVID-19: Consequences for higher education. The Lancet Oncology, 21(6), 758. https://doi.org/10.1016/S1470-2045(20)30287-4

Burnham, G. M. (2008). Chapter 1: Disaster definitions. In: Burnham GM \& Rand EC, editor(s). The Johns Hopkins and Red Cross and Red Crescent Public health guide in emergencies. Second edition. Geneva: International Federation of Red Cross and Red Crescent Societies. Available from: https:// reliefweb.int/sites/reliefweb.int/files/resources/Forward.pdf.

Cascella, M., Rajnik, M., Aleem, A., Dulebohn, S. C., \& Di Napoli, R. (2021). Features, evaluation, and treatment of coronavirus (COVID-19). In StatPearls. StatPearls Publishing.

Chen, C. H., \& Mullen, A. J. (2020). COVID-19 can catalyze the modernization of medical education. JMIR Medical Education, 6(1), e19725. https://doi.org/10.2196/19725.

Choi, B., Jegatheeswaran, L., Minocha, A., Alhilani, M., Nakhoul, M., Mutengesa, E. (2020). The impact of the COVID-19 pandemic on final year medical students in the United Kingdom: a national survey. BMC Med Educ, 20(1), 206. Published 2020 Jun 29. https://doi.org/10.1186/ s12909-020-02117-1

Clark, J. (2003). Fear of SARS thwarts medical education in Toronto. BMJ, 326, 784.

Cole, B. (2020). 10,000 med school graduates in Italy skip final exam, get sent directly into health service to help fight COVID-19. Newsweek. Available at: https://www.newsweek.com/italy-coronavirusCOVID-19-medical-students-1492996. Accessed 21 Mar 2020.

Czerniewicz, L., Trotter, H., \& Haupt, G. (2019). Online teaching in response to student protests and campus shutdowns: Academics' perspectives. International Journal of Educational Technology in Higher Education, 16(1), 43.

Dar, O., Buckley, E. J., Rokadiya, S., Huda, Q., \& Abrahams, J. (2014). Integrating health into disaster risk reduction strategies: Key considerations for success. American Journal of Public Health, 104(10), 1811-1816. https://doi.org/10.2105/AJPH.2014.302134

Doshmangir, L., Mahbub Ahari, A., Qolipour, K., Azami-Aghdash, S., Kalankesh, L., Doshmangir, P., et al. (2020). East Asia's strategies for effective response to COVID-19: Lessons learned for Iran. Manage Strat Health Syst., 4(4), 370-373.

Ebrahimi, A. R., Ebrahimi, S., \& Ashkani, E. S. (2020). How COVID-19 pandemic can lead to promotion of remote medical education and democratization of education? Journal of Advances in Medical Education \& Professionalism, 8(3), 144-145.

Ferrel, M. N., \& Ryan, J. J. (2020). The impact of COVID-19 on medical education. Cureus, 12(3), e7492. https://doi.org/10.7759/cureus.7492

Gaillard, J. C., \& Mercer, J. (2012). From knowledge to action: Bridging gaps in disaster risk reduction. Progress in Human Geography, 37(1), 93-114. https://doi.org/10.1177/0309132512446717 
Gao, J., Tian, Z., \& Yang, X. (2020). Breakthrough: Chloroquine phosphate has shown apparent efficacy in treatment of COVID-19 associated pneumonia in clinical studies. Bioscience Trends., 14(1), 72-73.

Goh, P., Sandars, J. (2020). A vision of the use of technology in medical education after the COVID19 pandemic. MedEdPublish, 9(1), 49. https://doi.org/10.15694/mep.2020.000049.1

Guo, Y., Huang, Y. M., Huang, J., Jin, Y. Z., Jiang, W., Liu, P. L., Liu, F. J., Ma, J. X., Ma, J. Y., Wang, Y., Xie, Z., Yin, H., Zhao, C. S., Zhou, S. D., Zhang, J., Zheng, Z. J. (2020) COVID-19 pandemic: Global epidemiological trends and China's subsequent preparedness and responses. Zhonghua Liu Xing Bing Xue Za Zhi, 41(5), 643-648. https://doi.org/10.3760/cma.j.cn112338-20200301-00222. [Epub ahead of print]

Harvey, A. (2020). COVID-19: Medical schools given powers to graduate final year students early to help NHS. BMJ. https://doi.org/10.1136/bmj.m1227.[PubMed][CrossRef][GoogleScholar]

Hilburg, R., Patel, N., Ambruso, S., Biewald, M. A., \& Farouk, S. S. (2020). Medical education during the coronavirus disease-2019 pandemic: Learning from a distance. Advances in Chronic Kidney Disease, 27(5), 412-417. https://doi.org/10.1053/j.ackd.2020.05.017.

Holshue, M. L., DeBolt, C., Lindquist, S., Lofy, K. H., Wiesman, J., Bruce, H., Spitters, C., Ericson, K., Wilkerson, S., Tural, A., Diaz, G., Cohn, A., Fox, L., Patel, A., Gerber, S. I., Kim, L., Tong, S., Lu, X., Lindstrom, S., ... Pillai, S. K. (2020). Washington state 2019-nCoV case investigation team. New England Journal of Medicine, 382(10), 929-936.

Kenneth McIntosh M. COVID-19: Epidemiology, virology, and prevention. Available from: https://www. uptodate.com/contents/126981. Updated Aug 04, 2021.

Khlaif, Z. N., \& Salha, S. (2020). The unanticipated educational challenges of developing countries in COVID-19 crisis: a brief report. Interdisciplinary Journal of Virtual Learning in Medical Sciences, 11(2), 130-134. https://doi.org/10.30476/ijvlms.2020.86119.1034

Kitzinger J. (1995). Qualitative research. Introducing focus groups. BMJ (Clinical research ed.), 311(7000), 299-302. https://doi.org/10.1136/bmj.311.7000.299

Lankarani, K. B., Alavian, S. M., \& Peymani, P. (2013). Health in the Islamic Republic of Iran, challenges and progresses. Medical Journal of the Islamic Republic of Iran, 27(1), 42-49.

Lomis, K., Amiel, J. M., Ryan, M. S., Esposito, K., Green, M., Stagnaro-Green, A., Bull, J., Mejicano, G. C., \& AAMC Core EPAs for Entering Residency Pilot Team (2017). Implementing an entrustable professional activities framework in undergraduate medical education: Early lessons from the AAMC core entrustable professional activities for entering residency pilot. Academic Medicine : Journal of the Association of American Medical Colleges, 92(6), 765-770. https://doi.org/10.1097/ ACM.0000000000001543

Marandi, A. (1996). Integrating medical education and health services: The Iranian experience. Medical Education, 30(1), 4-8. https://doi.org/10.1111/j.1365-2923.1996.tb00709.x

Mehrabi, N. (2014). The practical role of communication and information technology tools in crisis management. Paramedical Sciences and Military Health, 9(1), 48-53.

Mofijur, M., Fattah, I., Alam, M. A., Islam, A., Ong, H. C., Rahman, S., Najafi, G., Ahmed, S. F., Uddin, M. A., \& Mahlia, T. (2021). Impact of COVID-19 on the social, economic, environmental and energy domains: Lessons learnt from a global pandemic. Sustainable Production and Consumption, 26, 343-359. https://doi.org/10.1016/j.spc.2020.10.016.

O'Byrne, L., Gavin, B., \& McNicholas, F. (2020). Medical students and COVID-19: The need for pandemic preparedness. Journal of Medical Ethics, 46(9), 623-626. https://doi.org/10.1136/medet hics-2020-106353

Patil, N. G., Chan, Y., \& Yan, H. (2003). SARS and its effect on medical education in Hong Kong. Medical Education, 37(12), 1127-1128. https://doi.org/10.1046/j.1365-2923.2003.01723.x

Perlman, S. (2020). Another decade, another coronavirus. New England Journal of Medicine., 382(8), $760-762$.

Rose, S. (2020). Medical student education in the time of COVID-19. JAMA, 323(21), 2131-2132. https://doi.org/10.1001/jama.2020.5227. Available from: https://jamanetwork.com/journals/jama/ fullarticle/2764138.

Sahi, P. K., Mishra, D., \& Singh, T. (2020). Medical education amid the COVID-19 pandemic. Indian Pediatrics, 57(7), 652-657. https://doi.org/10.1007/s13312-020-1894-7

Shraim, K., \& Khlaif, Z. (2010). An e-learning approach to secondary education in Palestine: Opportunities and challenges. Information Technology for Development., 16(3), 159-173. 
Taghrir, M. H., Borazjani, R., \& Shiraly, R. (2020). COVID-19 and Iranian medical students; A survey on their related-knowledge, preventive behaviors and risk perception. Archives of Iranian Medicine, 23(4), 249-254. https://doi.org/10.34172/aim.2020.06

Traxler, J., Khaif, Z., Nevill, A., Affouneh, S., Salha, S., Zuhd, A., \& Trayek, F. (2019). Living under occupation: Palestinian teachers' experiences and their digital responses. Research in Learning Technology., 27, 27.

UNESCO. COVID-19 Education Response. Global Education Coalition, Available from: https://en.unesco.org/COVID19/educationresponse/globalcoalition. Accessed 5 Apr 2020.

United Nations, Hyogo Framework for Action 2005-2015: Building the Resilience of Nations and Communities to Disasters, 22 January 2005, A/CONF.206/6, available at: https://www.refworld.org/ docid/42b98a704.html. Accessed 11 Aug 2021.

Wayne, D. B., Green, M., \& Neilson, E. G. (2020). Medical education in the time of COVID-19. Science Advances, 6(31), eabc7110. https://doi.org/10.1126/sciadv.abc7110

Publisher's note Springer Nature remains neutral with regard to jurisdictional claims in published maps and institutional affiliations.

\section{Authors and Affiliations}

\section{Zahra Karimian $^{1,2}$ (D) Majid Reza Farrokhi ${ }^{3,4}$ (D) Mohsen Moghadami $^{5}$ (D) Nahid Zarifsanaiey ${ }^{1}$ (D) Manoosh Mehrabi ${ }^{1}$ (D) Laleh Khojasteh $^{6}$. Nasim Salehi ${ }^{7}$}

Zahra Karimian

Karimian@sums.ac.ir

Mohsen Moghadami

Moghadami@sums.ac.ir

Nahid Zarifsanaiey

Nzarifsanaee@gmail.com

Manoosh Mehrabi

Mehrabi.manoosh@gmail.com

Laleh Khojasteh

Khojastehlaleh@yahoo.com

Nasim Salehi

Nasim.Salehi@scu.edu.au

1 Department of E-Learning in Medical Sciences, Virtual School and Center of Excellence in E-Learning, Shiraz University of Medical Sciences, Shiraz, Iran

2 Virtual University of Medical Sciences, Tehran, Iran

3 Department of Neurosurgery, School of Medicine, Shiraz University of Medical Sciences, Shiraz, Iran

4 Neuroscience Research Center, Shiraz University of Medical Sciences, Shiraz, Iran

5 Department of Internal Medicine, School of Medicine, Shiraz University of Medical Sciences, Shiraz, Iran

6 Department of English Language, School of Paramedical Sciences, Shiraz University of Medical Sciences, Shiraz, Iran

7 Faculty of Health, Southern Cross University, Gold Coast, QLD, Australia 